\title{
Análisis microbiológico del agua para consumo humano de la población del centro poblado pachapiriana, distrito de chontalí, provincia de Jaén- 2019
}

Lucy Marlita. Mejía Taboada

lucy192013@ hotmail.com

Licenciado en Tecnología Médica especialidad Laboratorio Clínico y Anatomía Patológica Facultad de ciencias de la Salud.

Escuela de Tecnología Médica.

Universidad Nacional de Jaén. Cajamarca, Perú.

María Editha. Zelada Herrera edyze19@hotmail.com

Licenciado en Tecnología Médica especialidad Laboratorio Clínico y Anatomía Patológica.

Facultad de ciencias de la Salud. Escuela de Tecnología Médica. Universidad Nacional de Jaén. Cajamarca, Perú.

Dr. Luis Omar Carbajal García lcarbajalg@hotmail.com Docente, Jaén, Perú. Facultad de ciencias de la Salud. Escuela de Tecnología Médica Universidad Nacional de Jaén. Cajamarca, Perú.

\section{RESUMEN}

El presente trabajo de investigación denominado "Análisis microbiológico del agua para consumo humano de la población del Centro Poblado Pachapiriana, Distrito de Chontalí, Provincia de Jaén- 2019" cuyo objetivo fue determinar el nivel de contaminación microbiológica del agua de consumo humano en el Centro Poblado Pachapiriana, Distrito de Chontalí, Provincia de Jaén - 2019, de 120 viviendas se consideró para el estudio 40 viviendas y 4 pozos de abastecimiento de agua. En la investigación trabajamos con la Técnica del Número Más Probable en la cual obtuvimos como resultados que las muestras tienen que ser $<1,8 / 100 \mathrm{ml}$; mientras que los resultados obtenidos son $>6.8 / 100 \mathrm{ml}$ 
elevado para coliformes totales, para coliformes fecales dio como resultado $>4 / 100 \mathrm{ml} \mathrm{y}$ para E. Coli; si se obtuvieron tres muestras $(9-18$ y 31$)$ con el valor indicado del D.S. $\mathrm{N}^{\mathrm{o}}$ 031-2010 que es $<1,8 / 100 \mathrm{ml}$, las 37 muestras restantes tienen presencia de E coli por que el resultado es $>2 / 100 \mathrm{ml}$. Se concluye que, con base a la prueba presuntiva, confirmativa y completa realizadas, se determinó que el agua que se abastece al C.P. Pachapiriana, no reúne las condiciones microbiológicas para ser considerada apta para el consumo humano debido a que todas las muestras presentan un NMP importante de coliformes fecales, totales y E. coli lo que indica que el agua está contaminada con materia fecal.

Palabras claves: contaminación del agua; coliformes fecales; coliformes totales; inocua 


\title{
Microbiological analysis of water for human consumption of the population of the Pachapiriana town center, Chontalí district, Jaén province - 2019
}

\begin{abstract}
ABSTRAC
This research paper called "Microbiological analysis of water for human consumption of the population of the Pachapiriana Village Center, District of Chontalí, Province of Jaén2019" whose objective was to determine the level of microbiological contamination of water for human consumption in the Town Center Pachapiriana, District of Chontalí, Province of Jaen - 2019, of 120 homes, 40 homes and 4 water supply wells were considered for the study. In the investigation we worked with the Most Probable Number Technique in which we obtained as results that the samples have to be $6.8 / 100 \mathrm{ml}$ elevated for total coliforms, for fecal coliforms it resulted in> 4/100 ml and for E. Coli; if three samples (9-18 and 31) were obtained with the indicated value of the D.S. No. 0312010 which is $2 / 100 \mathrm{ml}$. It is concluded that, based on the presumptive, confirmatory and complete test performed, it was determined that the water that is supplied to the C.P. Pachapiriana, does not meet the microbiological conditions to be considered suitable for human consumption because all samples have an important NMP of fecal coliforms, total and E. coli indicating that the water is contaminated with fecal matter.
\end{abstract}

Keywords: water pollution; faecal coliforms; total coliforms; innocuous.

Artículo recibido: 02 noviembre. 2021 Aceptado para publicación: 28 noviembre 2021 Correspondencia: lucy192013@ hotmail.com

Conflictos de Interés: Ninguna que declarar 


\section{INTRODUCCIÓN}

La Organización Mundial de la Salud (OMS), en sus guías para la calidad de agua potable del año 2004, señala que el riesgo más común y difundido que lleva consigo el agua potable son las enfermedades infecciosas causadas por bacterias, virus, protozoarios y helmintos. (1)

A nivel mundial alrededor de 1,8 millones de personas mueren cada año debido a enfermedades diarreicas (incluido el cólera); un 90\% de esas personas son niños menores de cinco años, principalmente procedentes de países en desarrollo. Además, se ha estimado que el $88 \%$ de las enfermedades diarreicas son producto de un abastecimiento de agua insalubre, de un saneamiento y una higiene deficiente. (2)

En el año 2013 en el Perú (3) Domínguez et al (3) identificó más de 20 enfermedades en las que el agua es un vehículo directo o indirecto en el contagio, algunas de ellas tienen un alto impacto en término de morbilidad y mortalidad, por contaminación con aguas servidas y excretas de humanos o de animales; indicando a la vez que la población que habita en los asentamientos humanos no cuenta con las condiciones sanitarias adecuadas, ni con acceso a agua de calidad y está calculada en $40.6 \%$.

Gutiérrez Feliciano (4), indicó que en Puno la población todavía consume agua contaminada con materia fecal; y es que sólo existen alrededor de 49 mil 900 conexiones domiciliarias en el sistema de agua potable, según la Empresa Prestadora de Servicios de Agua Potable y Alcantarillado (SEDA-Juliaca). Es decir, alrededor del 50\% de la población no cuenta con este servicio vital, por ello consume agua contaminada de pozos. El procedimiento mediante el cual se inspecciona el agua es el análisis microbiológico, el cual determina si presenta o no patógenos y, en caso de ser positivo, su carga (cantidad) y grado de patogenicidad. Los análisis microbiológicos se basan habitualmente en el cultivo y recuento de los microorganismos. (5)

La gestión de la calidad de agua para consumo humano garantiza su inocuidad y se rige específicamente por los siguientes lineamientos; prevención de enfermedades transmitidas a través del consumo del agua de dudosa o mala calidad. Desarrollo de acciones de promoción, educación y capacitación para asegurar que el abastecimiento, la vigilancia y el control de la calidad del agua para consumo, sean eficientes, eficaces y (6). El control de la calidad sanitaria de los recursos del ambiente puede llevarse a cabo mediante la enumeración de bacterias indicadoras de contaminación fecal. Estas bacterias 
pueden ser utilizadas para valorar la calidad de los alimentos, sedimentos y aguas destinadas al consumo humano, la agricultura, la industria y la recreación, ya que no existe un indicador universal, por lo que se debe seleccionar el más apropiado para la situación específica en estudio. Los indicadores de contaminación fecal más utilizados son los coliformes totales y termotolerantes, Escherichia coli y enterococos. (7)

Los coliformes totales son bacterias Gram negativas en forma bacilar que fermentan la lactosa a temperatura de 35 a 37 oC, produciendo ácido y gas (CO2) en 24 horas, aerobias o anaerobias facultativas, son oxidasa negativa, no forman esporas y presentan actividad enzimática de la B-galactosidasa. Entre ellos se encuentran los diferentes Escherichia coli, Citrobacter, Enterobacter y Klebsiella. (8)

La Klebsiella aerogenes son bacterias Gram negativas, anaerobias facultativas, de la familia de Enterobacterias, muchas son patógenas y son causa de infecciones oportunistas en huéspedes comprometidos generalmente hospitalizados, causa infección del tracto urinario y de tracto respiratorio. (9) Se encuentra en el tracto digestivo humano, aunque también libremente en el suelo y de agua; sus colonias son grandes y mucosas, algunas cepas llegan a formar cápsula, como fuente de carbono pueden utilizar glucosa y lactosa, no forman sulfato de hidrogeno. (10)

Los coliformes termotolerantes, soportan temperaturas hasta de $45 \mathrm{oC}$, comprenden un grupo muy reducido de microorganismos los cuales son indicadores de calidad, ya que son de origen fecal. En su mayoría están representados por el microorganismo E.coli pero se pueden encontrar, entre otros menos frecuentes, Citrobacter freundii y Klebsiella pneumoniae estos últimos hacen parte de los coliformes termotolerantes, pero su origen se asocia normalmente con la vigilancia y solo ocasionalmente aparecen en el intestino (11).

E. coli es la única especie dentro de las Enterobacterias que presentan la enzima BDGlucoronidasa, que degrada el sustrato 4-metilumberiferil- $\beta$-D-glucorónico (MUG), formando 4-metilumbeliferona, este producto tiene la prioridad de emitir fluorescencia azul/verde cuando se ilumina con luz ultravioleta. (12)

Existen indicadores patógenos de transmisión fecal-oral la cual pueden estar presentes en el agua cruda (agua natural que no ha sido sometida a procesos de tratamiento para su potabilización), entre ellos bacterias como Salmonella spp., Shigella spp., coliformes totales y fecales, los cuales han sido encontradas en abastecimientos de agua (13). 
El reglamento de la calidad del consumo humano (D.S. Nº 031-2010-SA), a través de sus 10 títulos, 81 artículos, 12 disposiciones complementarias, transitarías y finales y 5 anexos; no solo establece límites máximos permisibles, en lo que a parámetros microbiológicos, parasitológicos, organolépticos, químicos, orgánicos e inorgánicos y parámetros radioactivos, le asigna nuevas y mayores responsabilidades a los Gobiernos Regionales, respecto a la vigilancia de la calidad del agua para consumo humano; además de fortalecer a la DIGESA, en el posicionamiento como autoridad sanitaria frente a estos temas. En el presente reglamento establece disposiciones generales con relación a la gestión de la calidad del agua para consumo humano, con finalidad de garantizar su inocuidad, prevenir los factores de riesgos sanitarios, así como proteger y promover la salud y el bienestar de la población; así mismo nos indican los parámetros microbiológicos y otros organismos (14)

Como antecedentes Nacionales se estudió a Sotomayor Cobos (15); en su investigación realizada en Ecuador donde obtuvo 38 muestras mensuales durante 4 meses, como resultados se obtuvo Coliformes totales $1800 \mathrm{NMP} / 100 \mathrm{ml}$ siendo el máximo permisible $<2 \mathrm{NMP} / 100 \mathrm{ml}$. En E. coli se encontró 700 NMP/100ml siendo el máximo permisible <1 NMP/100ml. Recuento de levaduras y mohos. Al no contar con una norma establecida para levaduras, no podemos determinar si el recuento de microorganismo cumple con estándares de calidad. En conclusión, se dice que algunas muestras con altas concentraciones evidencian la necesidad de tomar algunas medidas desde diferentes ámbitos.

Chong Rengifo (16), en su investigación realizada en Perú en 12 muestras (6 muestras de pozos artesanos y 6 de reservorios), como resultados se obtuvo bacterias heterotróficas el valor máximo encontrado fue $1300 \mathrm{UFC} / \mathrm{ml}$. En coliformes totales se encontró 1,6x105 $\mathrm{NMP} / 100 \mathrm{ml}$. coliformes termotolerantres 5,4x104 NMP/100ml; dando a conocer que, el agua de pozo y las aguas de la red de distribución del Centro Poblado Menor La Libertad están contaminadas con coliformes fecales.

Chambi Choque (17), en su estudio realizado al Agua de Consumo Humano del Centro Poblado de Trapiche- Ananea - Puno, consideró 54 muestras de agua distribuida en 10 piletas, 20 acequias y 24 pozos artesanales, obteniendo números de fuentes de abastecimiento contaminados y no contaminados; los mismos que fueron analizados a través de la prueba estadística de ji-cuadrado, y el NMP de coliformes y Escherichia coli, 
obteniéndose resultados de contaminación mayores en las piletas $70 \%$, pozos $54 \%$ y acequias $40 \%$; siendo el número más probable de Escherichia coli mayor en pozos 11.46 \pm 3.36 comparado a la de acequias y piletas que tuvieron $7.75 \pm 2.43$ y $6.28 \pm 2.21 \mathrm{NMP}$ de Escherichia coli, respectivamente $(\mathrm{P} \leq 0.05)$; determinándose que las tres fuentes de abastecimiento de agua NO ES APTO para consumo humano.

De acuerdo a todo lo mencionado anteriormente es necesario que se realice el estudio que va indicar cuál es la calidad microbiológica del agua de los posos de captación y las viviendas de los pobladores del Centro Poblado Pachapiriana, Distrito de Chontali debido a que existe la posibilidad que esté contaminada con bacterias coliformes, por el estado en que se encuentran sus pozos y color del agua que llega a las viviendas., estableciendo el siguiente problema a investigar: ¿Cuál es el nivel de contaminación microbiológica del agua de consumo humano en el Centro Poblado Pachapiriana - 2019?

Los principales beneficiarios de esta investigación serán para los trabajadores de la planta de agua y la población consumidora, ya que ayudará a determinar la presencia de bacterias coliformes que es el principal objetivo. Sin embargo, como se señaló antes, las directrices sobre la calidad de las aguas residuales y las normas para aprovechamiento frecuentemente se expresan según el máximo número permisible de bacterias coliformes totales. Puesto que no existe duda sobre el origen fecal de las aguas residuales, se supone que estos microorganismos se pueden emplear como indicadores de patogenicidad y que existe por lo menos una relación semicuantitativa entre las concentraciones de microorganismos patógenos y las de indicadores.

\section{MATERIALES Y MÉTODOS}

\section{Tipo de investigación}

- El presente estudio es descriptivo, porque fundamentalmente caracteriza fenómenos o situaciones concretas indicando sus rasgos más peculiares o diferenciadores.

\section{Población}

- La población de estudio está constituida por 100 viviendas que consumen agua entubada que la utilizan con diferentes fines, las viviendas que sirvieron para estudio pertenecen al Centro Poblado Pachapiriana, y se encuentra en el Distrito de Chontalí.

\section{Muestra}

- El estudio de las muestras se realizó de manera aleatoria sistemática donde se escogió 1 de cada 2 muestras llegadas al laboratorio. 


\section{Métodos, Técnicas, Instrumentos y Procedimientos de Recolección de Datos}

Según el "Protocolo de procedimientos para la toma de muestras, preservación, conservación, transporte, almacenamiento y recepción de agua para consumo humano"R.D. 24 de septiembre del 2015 - MINSA. (21)

\section{Procedimiento del muestreo}

\section{Ubicación y puntos de muestreo}

Se debe programar la ubicación y el número de muestras a tomar.

\section{Puntos fijos}

- En la captación

- A la salida del tratamiento de agua

- A la salida de la infraestructura de almacenamiento

\section{Puntos de interés colectivo}

- En las redes de distribución sectorizadas

\section{Toma de muestra}

- La toma de muestra se realizó por personal autorizado para la actividad, con el fin de asegurar que las muestras sean representativas del agua.

- El punto de muestreo debe ser identificado.

- Tomar en cuenta: que en la toma de muestra de los grifos se debe tener en cuenta que no exista ninguna fuga de los sellos y empaquetaduras del caño, remover cualquier dispositivo ajeno al grifo, luego procedemos a desinfectar el grifo interna y externamente previa a la toma de muestra con algodón o hiposo con alcohol al 70\% después abrir la llave y dejar que fluya durante 2 minutos antes de tomar la muestra; y para tomar la muestra en los pozos se debe asegurar un cordón de nylon de muestreo por medio del sujetador situado a un extremo y sumergir $30 \mathrm{~cm}$, tener cuidado que no rose con las paredes de la estructura y retirar.

\section{Rotulado e identificación de las muestras de agua}

Los frascos debemos identificarlos antes de la toma de muestra con una etiqueta, escrita con letra clara y legible, de preferencia utilizar plumón de tinta indeleble, sin borrones ni enmendaduras, la cual debe ser protegida con cinta adhesiva transparente conteniendo las siguientes datos con precisión:

- Código de identificación de campo

- Localidad, distrito, provincia, región 
- Punto de muestreo

- Matriz

- Fecha y hora de muestreo

- Muestreador

\section{Conservación y envió de muestras}

- Las muestras que recolectamos fueron conservadas en cajas térmicas (coolers) a temperaturas de $4^{\circ} \mathrm{c}$ (pero sin congelar).

- Los recipientes de vidrio fueron embalados con cuidado para evitar roturas, derrames y contaminaciones; trasladamos en cajas térmicas, aisladas de la influencia de la luz solar y con disponibilidad de espacio para la colocación del material refrigerante.

\section{Técnicas de Recolección de datos}

1) Se realizó encuestas para verificar cuál es su opinión acerca del agua que les brindan para su consumo.

2) Etapa de campo: En esta etapa de la investigación, se recolectaron 44 muestras de agua en recipientes de vidrio estéril con tapa de $250 \mathrm{ml}$ de capacidad, un volumen de $150 \mathrm{ml}$ de acuerdo a los puntos de muestreo seleccionados, utilizando para una mejor identificación de las muestras tomadas la ficha de registro de datos. Se transportará en condiciones de refrigeración para luego ser analizados.

3) Etapa de laboratorio: En esta etapa de la investigación, se efectuó el análisis bacteriológico de las muestras de agua a través del método Numero Más Probable (NMP), el análisis lo realizaremos en el laboratorio del Centro de Salud Morro Solar - Jaén; área de microbiología.

\section{RESULTADOS}

a. La muestra de la zona de captación es de 79/100 ml de contaminación por coliformes totales, 9.3/100 ml de coliformes fecales, debido a que no se encuentra cubierta; además, se encuentra ubicado en zona donde hay plantas. La muestra de la zona de sedimentación se encontró 49/100 $\mathrm{ml}$ de contaminación por coliformes totales, 6.8/100 $\mathrm{ml}$ de coliformes fecales, ya que no cuentan con una limpieza y desinfección adecuada. La muestra de la zona de reservorio con 27/100 ml de contaminación por coliformes totales, $6,8 / 100 \mathrm{ml}$ de coliformes fecales, ya que los reservorios no cuentan con una tapa fija y se encuentra expuesta a la intemperie que ingrese polvo, basura; y, la muestra tomada en el pozo de abastecimiento para las viviendas con 49/100 ml de contaminación de 
coliformes totales, 9.3/100 ml de coliformes fecales, este reservorio se encuentra en una altura promedio pero no tiene una tapa que cubra que las personas no introduzcan material de contaminación, las muestras no superan los límites permisibles máximos permisibles del Reglamento de la calidad de agua para el consumo humano.

\begin{tabular}{ccccccc}
\hline & \multicolumn{4}{c}{ COLIFORMES TOTALES } & \multicolumn{2}{c}{ NUMERO MAS PROBABLE } \\
\cline { 2 - 7 } $\begin{array}{c}\text { Muestra } \\
\text { Pozos }\end{array}$ & $\begin{array}{c}\text { Prueba } \\
\text { Confirmativa }\end{array}$ & NMP & $\mathbf{1 0 0}$ g. & NMP \\
\cline { 2 - 7 } & $\mathbf{1 0}$ & $\mathbf{1}$ & $\mathbf{0 , 1}$ & $\mathbf{1 0 0} \mathbf{~ m l}$ & $\begin{array}{c}\text { Pos* } \\
\mathbf{1 0 ; 1 ; 0 , 1}\end{array}$ & $\mathbf{1 0 0} \mathbf{~ m l}$ \\
\hline A & $\mathbf{5}$ & $\mathbf{3}$ & $\mathbf{0}$ & $\mathbf{7 9}$ & 530 & 79 \\
\hline B & $\mathbf{5}$ & $\mathbf{2}$ & $\mathbf{0}$ & $\mathbf{4 9}$ & 520 & 49 \\
\hline C & $\mathbf{4}$ & $\mathbf{3}$ & $\mathbf{0}$ & $\mathbf{2 7}$ & 430 & 27 \\
\hline D & $\mathbf{5}$ & $\mathbf{2}$ & $\mathbf{0}$ & $\mathbf{4 9}$ & 520 & 49 \\
\hline
\end{tabular}

\section{A= Zona de captación}

\section{$B=$ Cámara de sedimentación \\ C= Cámara de filtración \\ $D=$ Reservorio}

\begin{tabular}{|c|c|c|c|c|c|c|}
\hline \multirow{3}{*}{$\begin{array}{c}\text { Muestra } \\
\text { de } \\
\text { Pozos }\end{array}$} & \multicolumn{4}{|c|}{ COLIFORMES FECALES } & \multicolumn{2}{|c|}{ NUMERO MAS PROBABLE } \\
\hline & \multicolumn{3}{|c|}{$\begin{array}{c}\text { Prueba } \\
\text { Confirmativa }\end{array}$} & \multirow{2}{*}{$\begin{array}{c}\text { NMP } \\
100 \mathrm{ml}\end{array}$} & \multirow{2}{*}{$\begin{array}{c}100 \text { g. } \\
\text { Pos* } \\
\text { 10;1;0,1 }\end{array}$} & \multirow{2}{*}{$\begin{array}{l}\text { NMP } \\
100 \mathrm{ml}\end{array}$} \\
\hline & 10 & 1 & 0,1 & & & \\
\hline $\mathbf{A}$ & 2 & 2 & $\mathbf{0}$ & 9,3 & 220 & 9,3 \\
\hline B & 2 & $\mathbf{1}$ & $\mathbf{0}$ & 6,8 & 210 & 6,8 \\
\hline $\mathbf{C}$ & 2 & $\mathbf{1}$ & $\mathbf{0}$ & 6,8 & 210 & 6,8 \\
\hline D & 2 & 2 & $\mathbf{0}$ & 9,3 & 220 & 9,3 \\
\hline
\end{tabular}

\section{A= Zona de captación \\ B= Cámara de sedimentación \\ C= Cámara de filtración \\ $\mathrm{D}=$ Reservorio}

b. En la tabla 2 se presenta la evaluación de la calidad de agua de acuerdo al procesamiento de datos de las encuestas realizadas a cada jefe de familia de las 40 viviendas, los que 
indicaron que el agua que consumen no es de buena calidad, determinándose en los promedios de sus respuestas que el 100\% se ubican en la categoría "mala", esto indica que el agua del Centro Poblado Pachapiriana no es tratada correctamente.

\begin{tabular}{lcc} 
& \multicolumn{2}{c}{ Frecuencia } \\
\cline { 2 - 3 } \multicolumn{1}{c}{ Categoría } & Cantidad & Porcentaje \\
\hline Mala & 40 & $100,00 \%$ \\
\hline Buena & 0 & $0,00 \%$ \\
\hline Excelente & 0 & $0,00 \%$ \\
\hline Total & $\mathbf{4 0}$ & $\mathbf{1 0 0 , 0 0 \%}$ \\
\hline
\end{tabular}

c. En la tabla 3 se muestra que de las 40 muestras 2 tienen NMP más alto: la muestra 10 en la que se encontró $350 / 100 \mathrm{ml}$ coliformes totales y la muestra 9 con 220/100 ml de coliformes totales, viviendas se encuentra ubicadas a una distancia de 3 metros del pozo de distribución. Las demás muestras tomadas y procesadas tampoco cumplen con los límites máximos permisibles, de acuerdo al reglamento de calidad de agua para el consumo humano. (DS N $\mathrm{N}^{\circ}$ 031-2010-SA).

\begin{tabular}{cccc}
\multicolumn{2}{c}{ Coliformes totales } & Coliformes fecales & Límite máximo permisible \\
\cline { 1 - 2 } $\mathbf{N M P}$ & $\mathbf{N}^{\mathbf{0}}$ de viviendas & $\mathbf{N}^{\mathbf{0}}$ de viviendas & $<1,8 / 100 \mathrm{ml}$ \\
\hline $\mathbf{2} \mathbf{- 1 2}$ & 16 & 30 & $<1,8 / 100 \mathrm{ml}$ \\
\hline $\mathbf{1 3} \mathbf{- 2 3}$ & 14 & 10 & $<1,8 / 100 \mathrm{ml}$ \\
\hline $\mathbf{2 4} \mathbf{- 3 4}$ & 7 & 0 & $<1,8 / 100 \mathrm{ml}$ \\
\hline $\mathbf{3 5} \mathbf{- 4 5}$ & 1 & 0 & $<1,8 / 100 \mathrm{ml}$ \\
\hline $\mathbf{2 2 0}$ & 1 & 0 & $<1,8 / 100 \mathrm{ml}$ \\
\hline $\mathbf{3 5 0}$ & 1 & 0 & \\
\hline
\end{tabular}

d. En la tabla 4 se presenta las 40 muestras tomadas de las viviendas del C.P. Pachapiriana, donde los resultados fueron positivos para coliformes totales, coliformes fecales y Escherichia colí ya que pasan el límite establecido que es < 1,8/100 ml NMP esto significa que no cumplen con los límites máximos permisibles, de acuerdo al reglamento de calidad de agua para el consumo humano. (DS N 031-2010-SA) 


\begin{tabular}{ccccc}
\hline \multicolumn{2}{c}{ Coliformes totales } & $\begin{array}{c}\text { Coliformes } \\
\text { fecales } \\
\mathbf{N}^{\mathbf{0}} \text { de } \\
\text { viviendas }\end{array}$ & $\begin{array}{c}\text { Escherichia } \\
\text { colí } \\
\mathbf{N}^{\mathbf{0}} \text { de } \\
\text { viviendas }\end{array}$ & Límite máximo permisible \\
\hline $\mathbf{N M P}$ & $\begin{array}{c}\mathbf{0}^{\mathbf{0}} \text { de } \\
\text { viviendas }\end{array}$ & 0 & 3 & $<1,8 / 100 \mathrm{ml}$ \\
\hline $\mathbf{1 , 8}$ & 0 & 30 & 35 & $<1,8 / 100 \mathrm{ml}$ \\
\hline $2-12$ & 16 & 10 & 2 & $<1,8 / 100 \mathrm{ml}$ \\
\hline $\mathbf{1 3} \mathbf{- 2 3}$ & 14 & 0 & 0 & $<1,8 / 100 \mathrm{ml}$ \\
\hline $\mathbf{2 4} \mathbf{- 3 4}$ & 7 & 0 & 0 & $<1,8 / 100 \mathrm{ml}$ \\
\hline $\mathbf{3 5} \mathbf{- 4 5}$ & 1 & 0 & 0 & $<1,8 / 100 \mathrm{ml}$ \\
\hline $\mathbf{2 2 0}$ & 1 & 0 & 0 & $<1,8 / 100 \mathrm{ml}$ \\
\hline $\mathbf{3 5 0}$ & 1 & & & \\
\hline
\end{tabular}

e. En la tabla 5 se presentan los resultados de las 4 muestras tomadas en los pozos de abastecimiento de agua al C.P. Pachapiriana, donde se puede observar que no cumplen con el límite establecido $<1,8 / 100 \mathrm{ml} \mathrm{NMP}$ esto quiere decir que las muestras son positivas para coliformes totales, fecales y E. colí; no cumpliendo los límites máximos permisibles, de acuerdo al reglamento de calidad de agua para el consumo humano. (DS $\mathrm{N}^{\circ}$ 031-2010-SA)

\begin{tabular}{ccccc}
\hline $\begin{array}{c}\text { Muestra } \\
\text { de }\end{array}$ & $\begin{array}{c}\text { Coliformes } \\
\text { totales }\end{array}$ & $\begin{array}{c}\text { Coliformes } \\
\text { fecales }\end{array}$ & $\begin{array}{c}\text { Escherichia } \\
\text { colí }\end{array}$ & Límite máximo permisible \\
\cline { 2 - 4 } Pozos & NMP & NMP & NMP & \\
\hline $\mathrm{A}$ & 79 & 9.3 & 2.0 & $<1,8 / 100 \mathrm{ml}$ \\
\hline $\mathrm{B}$ & 49 & 6.8 & 4.0 & $<1,8 / 100 \mathrm{ml}$ \\
\hline $\mathrm{C}$ & 27 & 6.8 & 4.0 & $<1,8 / 100 \mathrm{ml}$ \\
\hline $\mathrm{D}$ & 49 & 9.3 & 4.0 & $<1,8 / 100 \mathrm{ml}$ \\
\hline
\end{tabular}

\section{DISCUSIÓN}

De acuerdo a las muestras procesadas de los 4 pozos, el resultado indica que están contaminados, tal como se muestra en la tabla 01 , donde se puede apreciar que la zona de captación la contaminación es de 79/100 ml de coliformes totales, 9.3/100 ml de coliformes fecales; siendo un posible factor de contaminación el abandono en que se encuentra, los restos de plantas en su interior, concentración alta de algas verdes de agua dulce. La muestra tomada en la zona de sedimentación, dio como resultado 49/100 ml de contaminación por coliformes totales, $6.8 / 100 \mathrm{ml}$ de coliformes fecales, siendo un posible efecto la falta de limpieza y desinfección adecuada. La muestra tomada en la zona de filtración arrojo el resultado de 27/100 ml de contaminación por coliformes totales, 
6,8/100 ml de coliformes fecales, siendo un posible foco de infección que el pozo se encuentre expuesto a la intemperie del polvo, basura, y otros restos; $\mathrm{y}$, la muestra tomada en el reservorio, resulto con 49/100 ml de contaminación de coliformes totales, 9.3 /100 $\mathrm{ml}$ de coliformes fecales, siendo un posible factor que el pozo no tenga cobertura que lo proteja de efectos contaminantes, por lo que resulto que las 04 muestras tomadas en los pozos de abastecimiento de agua del Centro Poblado de Pachapiriana no superen los límites máximos permisibles del Reglamento de la calidad de agua para el Consumo Humano; resultados que son similares con el estudio realizado por Chong (16) donde indica que el agua de pozo y las aguas de la red de distribución del Centro Poblado Menor La Libertad se encontró muestras contaminadas de coliformes totales 1,6x105 $\mathrm{NMP} / 100 \mathrm{ml}$; coliformes termotolerantres 5,4x104 NMP/100ml; así como también lo determinado por Sotomayor (15) porque se obtuvo 38 muestras mensuales durante 4 meses, como resultados se obtuvo coliformes totales $1800 \mathrm{NMP} / 100 \mathrm{ml}$ siendo el máximo permisible <2 NMP/100ml. En E. coli se encontró $700 \mathrm{NMP} / 100 \mathrm{ml}$ siendo el máximo permisible <1 NMP/100ml.

Referente a la evaluación de la calidad de agua de acuerdo al procesamiento de datos de las encuesta realizada a cada jefe de familia de las 40 viviendas, nos indica que la categoría "mala" tiene un porcentaje de $100 \%$ esto indica que el agua del Centro Poblado Pachapiriana no es tratada correctamente; resultados que son idénticos con el estudio realizado por Chong (16) donde indica que la salubridad humana es una de las principales preocupaciones del hombre, dadas las consecuencias negativas de su descuido; en este contexto es que las sociedades en su conjunto suman capacidades para realizar un seguimiento a la calidad de las fuentes de agua para consumo humano, logrando, en muchas ocasiones, revertir en forma oportuna, las consecuencias contraproducentes, mediante acciones precisas que conllevaron ingentes esfuerzos humanos y económicos. Sin embargo, existen lugares donde esta salubridad no es prioridad, como suele suceder en las comunidades alejadas de las zonas urbanas.

De los resultados obtenidos en las pruebas realizadas a las 40 muestras tomadas en las viviendas se puede indicar que ninguna cumple con los límites máximos permisibles del reglamento de calidad de agua para el consumo humano, siendo los resultados más resaltantes la muestra 9 que tiene 220/100 ml y la muestra 10 con 350/100 ml para coliformes totales; $y$, para coliformes fecales la muestra 10 y 12 resultaron con el NMP 
de 21/100 ml, viviendas que se encuentra ubicadas a una distancia cercana al pozo de distribución. Estos resultados son similares con el estudio realizado por Chambi (17) que considero en su estudio 54 muestras de agua que se obtuvo de 10 piletas, de 20 acequias y de 24 pozos artesanales, resultado con mayor contaminación las piletas 70\%, pozos $54 \%$ y acequias $40 \%$, determinándose que las tres fuentes de abastecimiento de agua no es apto para consumo humano; además, se determino en la evaluación del estado sanitario de la infraestructura de abastecimiento de agua, están deteriorados debido a que no se programa mantenimiento a la infraestrusctura, tal como sucede en el sistema de infraestructura de abastecimiento de agua motivo de la presente investigaciòn.

También se pudo determinar que las muestras de las viviendas y de los pozos no cumplen con los Limites máximo permisible para coliformes totales, coliformes fecales y Escherichia coli establecidos en el Reglamento de la Calidad del Agua para consumo humano (DS $\mathrm{N}^{\circ}$ 031-2010-S.A.); datos que son similares al estudio realizado por Sotomayor (15) donde obtuvo resultados mayores al límite máximo permisible para coliformes totales y para $E$. coli evidenciando la necesidad de tomar medidas inmediatas; también hay una similitud con el estudio realizado por Chambi Choque (17) donde se determinó que las muestras procesadas estaban contaminadas y excedían el Número Más Probable de coliformes y Escherichia coli, considerando el abastecimiento de agua como no apto para el consumo humano.

Respecto al objetivo y la hipótesis planteada en la investigación, se determinó que el nivel de contaminación del agua de consumo humano no cumple con los parámetros, las 44 muestras trabajadas tuvieron una incidencia mayor a 1,8/100 ml. Esto nos indica que los resultados obtenidos en la red de distribución y en las viviendas están contaminadas por que el Límite máximo permisible no cumple con el Reglamento de la calidad de agua para consumo humano (D.S. No 031-2010-SA), siendo las causas más importantes, la falta de mantenimiento y que no contengan una tapa por eso está expuesto a contaminación ambiental.

\section{CONCLUSIÓN}

1) Con base a la prueba presuntiva, confirmativa y completa realizadas, se determinó que el agua que se abastece al C.P. Pachapiriana, no reúne las condiciones microbiológicas para ser considerada apta para el consumo humano debido a que todas las muestras presentan un NMP importante de coliformes fecales, totales y E. colí. 
2) Según la encuesta aplicada se concluyó que la calidad de agua que consume la población no es adecuada según el procesamiento de datos realizada a cada jefe de familia de las 40 viviendas.

3) De la evaluación realizada a las muestras tomadas en las 40 viviendas, se determinó que existe contaminación en todas para coliformes totales y para coliformes fecales; mientras que, para E. coli 37 muestras resultaron mayores a lo permitido por el D.S $\mathrm{N}^{\circ}$ 031-2010 SA.

4) De acuerdo a la técnica del NMP, 100\% de muestras de agua de las viviendas no son aptas para el consumo humano, según el D.S No 031-2010 indica que las muestras tienen que ser $<1,8 / 100 \mathrm{ml}$; mientras que los resultados obtenidos son $>6.8 / 100 \mathrm{ml}$ elevado para coliformes totales, mientras que para coliformes fecales dio como resultado $>4 / 100 \mathrm{ml}$ y para $E$. colí; si se obtuvieron tres muestras $(9-18$ y 31$)$ con el valor indicado del D.S. $\mathrm{N}^{\circ}$ 031-2010 que es $<1,8 / 100 \mathrm{ml}$, las 37 muestras restantes tienen presencia de $E$.colí por que el resultado es $>2 / 100 \mathrm{ml}$.

\section{REFERENCIAS BIBLIOGRÁFICAS}

Chambi Choque , G. (2015). Determinación de Bacterias Coliformes y E. Coli en Agua de Consumo Humano del Centro Poblado de Trapiche-Ananea - Puno. Tesis para obtar titulo profesional, Universidad Nacional del Altiplano, Puno. Obtenido de http://repositorio.unap.edu.pe/handle/UNAP/1922

Chong Rengifo, A. (2010). Evaluación de la calidad del agua subterránea en el centro poblado menor la Libertad, distrito de San Rafael, provincia de Bellavista, región San Martín - Perú. [Tesis de maestria], Universidad Nacional de San Martín Tarapoto, Perù.

Dirección General de Salud Ambiental del Ministerio de Salud. ( Febrero de 2011). Reglamento de la Calidad del Agua para Consumo Humano: D.S. N 031-2010SA /. Reglamento de la Calidad del Agua para Consumo Humano, 44. Lima, Perú.

Domínguez, N., Jonis, M., Carrasco, S., Rivera, L., Menacho, A., Reyes, G., . . Vilca, F. (2013). Perfil microbiologico del agua destinada a consumo humano de un asentamiento humano en Lima - Perù. Revista de la facultad de Medicina Humaa de la Universidad Ricardo Palma(2), 13-17. 
Felix Fuentes, A., Campas Baypoli, O., Aguilar Apodaca, M., \& Meza Montenegro, M. (2007). Calidad microbiológica del agua de consumo humano de tres comunidades rurales del sur de Sonora (México). Salud Publica y nutriciòn(3).

Garcia , Y. (2009). Analisis Clinicos. Obtenido de [En línea].mailxmail.com: http://www.mailxmail.com/cursoanalisis

Gutiérrez, F. (2015). El drama de Chilla, toman agua contaminada con heces. Grupo La República Digital;. Obtenido de http://larepublica.pe/impresa/sociedad/359426el-drama-de-chillatoman-agua-contaminada-con-heces

Hayes, P. (1993). Microbiologia e higiene de los alimentos. En Microbiologia e higiene de los alimentos. Zaragoza España: Acribia.

Kwang- Pyo, K., Jochen, K., \& Loessner, M. (2006). Enterobacter sakazakii bacteriophages can prevent bacterial growth in reconstituted infant formula. En International journal of food microbiology (págs. 115. 195 - 203).

Larrea Murrell, J. A., Rojas Badía, M. M., Romeu Álvarez, B., Rojas Hernández, N., \& Heydrich Pérez, M. M. (2013). Bacterias indicadoras de contaminación fecal en la evaluación de calidad de las aguas. En Revision de la literatura. La Habana Cuba.

Manafi , M. (1998). New approaches for the fast detection of the fast detection of indicators, in particular enzyme detection methods(EDM).

Ministerio de Salud. (9 de julio de 1997). Ley N 26842 - Ley General de Salud. Lima, Perú.

Ministerio de Salud. (15 de seotiembre de 2015). Protocolo de procedimientos para la toma de muestras, preservación, conservación, transporte, almacenamiento y recepción de agua para consumo humano. Obtenido de www.digesa.minsa.gob.pe

Ocasio , N., \& Lopez, M. (2004). El uso del cloro en la desinfecciòn del agua. Recuperado el 18 de octubre de 2008, de http:/www.edustatipr.com/proyectos/inv97-98-11-3.pdf.

Organizaciòn Mundial de la salud. (1998). Guia sobre los requisitos de las practicas adecuadas de fabricaciòn.

Shekhar, N., C.P, \& Laxman, N. (2007). Journal of Ethnopharmacology(3), 446-451. 
Sotomayor Cobos, J. (2014). Análisis de la concentración de microorganismos en el agua para consumo humano, en San Cristóbal, Provincia de Galápagos. [Tesis de titulación], Universidad San Francisco de Quito, Ecuador.

SUNASS. (2004). La calidad del agua potable en el Perù. 40-49. 